\title{
AN ALTERNATIVE ETHICS FOR RESEARCH: LEVINAS AND THE UNHEARD VOICES AND UNSEEN FACES
}

\begin{abstract}
Some social scientists have criticised the workings of research-ethics committees because their biomedical model is ill-suited to social-science research in both practical and philosophical terms. In this paper we review these criticisms and propose an alternative approach to ethical review that is based on the philosophy of Emmanuel Levinas.
\end{abstract}

\section{Keywords}

Research ethics, ethical review, Levinas, the Other.

Word Count: 7335 (without bibliography), 8882 (with bibliography)

\section{Introduction and aims}

Before the 1990s the ethics of research outside in the revised paper section medicine were guided largely by the researcher's own morality and disciplinary guidance. Research funders and universities often knew little of how researchers proceeded until the results had been published. By the 1990s the legacy of wartime and medical tragedies had combined to create guidelines against which all research would be reviewed before it began. In this paper we argue that current procedures for ethical review have drawbacks for researchers in the social sciences and provide incomplete protection for those to be researched. Hence we propose a debate on the desirability of an alternative ethical stance for reviewing research, based on the work of Emmanuel Levinas.

\section{Research ethics and the social-science critique}

The history of research is punctuated by cases where the interests of those to be researched were subordinated to those of the researcher, with severe consequences for the former. In the Tuskagee case, some black Americans between 1932 and 1972 were deceived into thinking that they were receiving free health care, whereas they were part of a clinical trial studying how untreated syphilis developed (Belmont Report, 1978). In the Milgram case, participants were induced apparently to punish others when in fact they were unknowingly the subject of an experiment into obedience (Milgram, 1974). Serious issues of people's rights being unprotected had emerged during the Nuremberg trials, especially regarding the Holocaust and medical experimentation. These resulted in the Nuremberg Code of 1947 and the Declaration of Helsinki of 1964 (Leaning, 1996). These focused on protecting people involved in medical research by obtaining their informed consent to participation. Schüklenk (2000) argues that such protection is still less than total.

One of the most important documents providing guidance on the meaning and practice of ethics is the Belmont Report, created under the National Research Act of 1975 (National Commission for the Protection of Human Subjects of Biomedical and Behavioural Research, 1979, Weinstein 2008). Although not legally binding, Institutional Reviews Boards have used the Belmont Report as their main source for advice on ethics in research involving humans (Weinstein 2008). Since its inception it has become a model document for other official guidelines across different national research boards and institutions. The main objective of 
the Report was to 'provide an analytical framework that will guide the resolution of ethical problems arising from research including human subjects' (see Weijer 1999) and its influence has been far reaching. Three principles underwrite the Belmont Report: (i) respect for persons (autonomy), (ii) beneficence and (iii) justice.

In the Belmont Report respect for persons is conceptualised as: 'agents should be treated as autonomous agents, and [...] persons with diminished autonomy are entitled to protection' (Basic Ethical Principles, §2). An autonomous individual is defined as capable of deliberation about goals (Basic Ethical Principles, §3). The first principle comes into force through the guidelines provided for the process of informed consent: 'respect for persons requires that subjects, to the degree that they are capable, are given the opportunity to choose what shall or shall not happen to them' (Applications, §2). Beneficence consists of two components: 'do not harm' and 'maximise possible benefits and minimise harm' (Basic Ethical Principles, §7) recognising that harm may affect individuals or groups differently based on gender or ethnicity (Shore, 2006). In practice, this second principle is realised through the process of a risk-benefit assessment taking into account personal and wider societal norms and considerations (Shore, 2006). Often, beneficence is interpreted in a utilitarian sense, meaning doing the greatest good to the greatest number of people (Shore, 2006). Justice deals with 'who ought to receive the benefits of research and bear its burdens?' (Basic Ethical Principles, §11). Benefits are often conceived as relating to distributive justice and the Belmont Report gives further details how to assess the just distribution of burdens and benefits. It distinguishes between justice at the individual level - where fairness is used to select who should participate in risky research and who can benefit from research - and at the social level. Here the principle of social justice is introduced to draw a distinction between classes of subjects 'that ought, and ought not, to participate in any particular kind of research, based on the ability of members of that class to bear burdens on already burdened persons' (Applications, §20).

The main moral theory behind these three principles in the Belmont Report is Principlism (Weijer, 1999; Shore 2006) A prima facie principle is a normative standard deciding on the permissibility, rightness and obligatory nature of actions that fall within a principle but leaving scope to compromise, mediate or negotiate if needed (Weijer, 1999). Different normative standards can be used such as duty-based or consequentialist ethics, both clearly guiding the normative approach in the Belmont Report as discussed further later.

The major complaints against the ethical approach in the Belmont Report can be summarised as a complaint against procedural ethics (Guillemin and Gillam, 2004; Rossman and Rallis, 2010; Banks et al, 2013). Although applauded for protecting research participants, the Report has been criticised for being a checklist about the risks and benefits for the participants, confidentiality of data, consent and the use of plain language (Guillemin and Gillam, 2004). The problem with this procedural approach is that the decisions taken by a research ethics committee are separated from what actually happens during the research. It has also been suggested that research involving humans creates an intrinsic moral tension. Following the Kantian maxim, moral philosophy fails in bio-ethics (and research involving humans) because it does not respect the autonomy of individuals: people should never be used as a means to someone else's end (Guillemin and Gillam, 2004). An individual's decision should be led by his/her own interest and not the researcher's interest. The solution is to let the participants co-own the project's goals and not just be 'subjects'. One or even the way of achieving this is through prior informed consent. In other words, the Kantian maxim of respecting the autonomy of individuals can explain the 'tyranny' of informed consent and the 
obsession with the use of plain language in ethics review boards. Procedural ethics are thus the ruling force in Institutional Review Boards because they are perceived to be the best option for circumventing the intrinsic moral tension between respecting autonomy and research involving humans. This reasoning falls under the label of duty-based ethics. Another way of justifying rule-based ethics is consequentialist ethics drawing on the promotion of utility or well-being, values that are clearly embedded in the second principle of beneficence in the Belmont Report.

The legacy of the Belmont Report in the USA was most quickly felt in the biomedical sciences. It then permeated into procedures for non-medical research in the UK, notably through the Research Ethics Framework from the Economic and Social Research Council (ESRC, 2005). There had been precursors in the UK from the Association for Social Anthropologists (1999) and the British Sociological Association (2002/4). The ESRC set out ethical principles inspired by medicine, a review process with university ethical guidelines conforming to ESRC principles, and a checklist of requirements to be approved by a university Research Ethics Committee. The focus was on informed consent, freedom from coercion and the avoidance of harm to participants. While some medical-style safeguards may be 'difficult or impossible to quantify or anticipate in full prior to the start of a social science research project' and although 'informed consent maybe impracticable or meaningless in some research', nonetheless 'the researcher should seek informed consent where possible' (ESRC, 2005, p21). However, An EU Code of Ethics for Socio-Economic Research took a more nuanced view with even key principles such as informed consent being couched in terms of multiple debates, dilemmas and context (Dench, Iphofen and Huws, 2004, pp63-71).

However, the near-universal adoption by universities of ethics committees that apply to all research those national ethical principles devised for medical research, has generated debate and criticism. The American Anthropological Association (1998) stressed contingencies rather than universal principles in its ethical review of research. 'It is understood that the degree and breadth of informed consent required will depend on the nature of the project and may be affected by requirements of other codes, laws, and ethics of the country or community in which the research is pursued. Further, it is understood that the informed consent process is dynamic and continuous; the process should be initiated in the project design and continue through implementation by way of dialogue and negotiation with those studied'.

Schrag (2011), Hammersley (2009, 2015), Stanley and Wise (2010), Colnerud (2015) and Dingwall (2008) have summarised other issues. University research ethics committees may lack the disciplinary skills of the peer-review process and so may fail to appreciate the particuliarities of some disciplines and proposals. They may mandate general ethical principles that are unfeasible (Schrag, 2011; Monaghan, O’Dwyer and Gabe, 2013). Schrag (2011) argues that when committees spend their limited time resources on low-risk, socialscience research they are giving too little attention to, and so are harming, those in higher-risk science research. Dingwall (2008) goes further. The harm from social-science research is so limited that it is outweighed by the harm caused by researchers allegedly 'playing the ethics review game' - telling the committee what they want to hear, acting other than as approved or not doing necessary research, which would be a loss to society and academic freedom (Israel, 2014). Haggerty (2004) and Stanley and Wise (2010) highlight 'ethics creep', both in the prescriptions in the ESRC's ethics framework as it expanded from the 2005 version to the 
one in 2010, and in the operations of ethics committees. The definition of the 'harm' to be avoided is widening and the intensity of scrutiny increasing.

Further criticisms focus on the distinctiveness of the social sciences - often field sciences less able to foresee or plan events than in a laboratory. Ethnographers and anthropologists in particular have argued that their observational and narrative methods make the biomedical model particularly limiting (Atkinson, 2009; Smythe and Murray, 2000; Librett and Perrone, 2010). The latter argue that anonymity may be impossible, while Atkinson argues that ethical review is based on ethical protocols that 'do not match the social realities that the researchers themselves want to explore' hence 'contemporary regulation of social science research is sociologically and anthropologically illiterate' (p28). Wiles and Boddy (2013) query whether biomedically based ethical review can deal appropriately with research based on children, longitudinal studies, e-research and the secondary analysis of data. Crabtree (2013) makes a similar point regarding research on the experiences of vulnerable groups. Arguing that 'trust' is critical for researching vulnerable people long term, Pirrie et al. (2012) note that trust is a concept that sits uneasily in the protocols of current ethical review. Colnerud (2015) and Hammersley and Traianou (2011) both also make the point that current ethical review is excessive in some areas and inadequate in others that are outside the law, even if the latter are ethically important and problematic. Pollock (2012) makes a similar point on the potentially stifling effect of current ethical practices on the study of the vulnerable in the field, where microethics judgements are needed but disallowed.

Overall, it is argued that risk-averse institutions are demanding ethical standards, inspired by a biomedical model of universally applied principles, within a narrow definition of ethics that is inappropriate for much of the social sciences. Managerialism in universities and research funders requires risk management, documentation, the precise implementation of plans, and standardisation to achieve equity of treatment and auditability (McAreavey and Muir, 2011).

\section{The responses to the critique}

This critique has provoked responses that range from rejection to incorporating the critics' points in an improved ethical-review system. The strongest defence of prospective (i.e. preresearch) ethical review is from London (2012). He does not accord any research an opt-out. He shows why the benefits of prospective ethical review are real but hard to measure. The preparation for review weeds out poor proposals before submission. Inexperienced researchers are helped to learn the rules. He and Klitzman and Appelbaum (2012) acknowledge the dangers of committees nit-picking good proposals to show they are doing something. Hedgecoe's (2008) ethnographic study of research ethics committees failed to show any bias against, or misconstruction of social-science research. Jennings (2012) disputes that social-science research is always intrinsically low risk in terms of harm to participants. He contrasts the attempts at standardising NHS ethical-review processes with the lack of quality control over the university equivalents. Bond (2012), like Jennings (2012), accepts the force of Schrag's (2011) points and proposes reforms to avoid committees being hijacked by excessive concerns for remote contingencies in social-science research, while maintaining public trust (a point London (2012) also makes). His recommendation for improving ethical review for the social sciences is to focus less on harm reduction (often with an ever-widening definition of unlikely forms of harm) and instead to focus on rigour, respect and trust. Chenhall, Senior and Belton (2011) provide the anthropologist in the field with some practical ways of dealing with issues of consent, standardised guidelines and 
unexpected ethical dilemmas, while remaining within the principles used by research ethics committees. They stress the need for reflexivity, microethics and respect for local conditions.

\section{Insights from research in various contexts and cultures}

Many researchers working in different contexts and cultures have reported additional concerns about the practicality and appropriateness of the ethics codes debated so far in this paper. The first problem is that researchers are unclear how to react when unforeseen ethical issues arise in the field (as they often do) when the structure of ethical review is based on prospective review and approval. A further review of revised plans may be impracticable. Simply reporting afterwards changes of ethical importance is easy for the researcher but may devalue the ethical-review process.

The second set of issues is practical. How do you obtain informed consent if the local language does not contain words that are the equivalent in meaning to those one would normally use in, say, English, e.g. 'placebo' (Krosin et al., 2006)? How do you record informed consent in a pre-literate society? Many sheets with crosses prove nothing though they meet the procedural requirement. How do you persuade people to sign a consent form when they fear signing anything in case of negative repercussions? If 'research' in general is viewed with suspicion, and if some people are less willing to answer truthfully questions on sensitive topics (Bleek, 1987), then the cultural underpinnings of 'consent' for 'research' are very different. From whom should consent be obtained in societies where absolute individual autonomy is not the norm - from the community leader, the husband, the individual or from all of them, each having a veto (Agulanna, 2010; Adu-Gyamfi, 2014)? And can the individual realistically be autonomous and refuse when their elders agree?

These concerns lead on to a much wider debate over cultural imperialism (or objectivism) and cultural relativism. Should 'Western' ethical standards and procedures be imposed on everyone everywhere because they are the best - even if 'gold standard' only by Western norms - and because they sit comfortably with Western researchers, funders and institutions? Or should ethical practice be tailored to local norms? This can become a rather sterile dualistic debate lacking an agreed resolution. Corradetti's proposal (2009) for a 'universal pluralism' may be a way forward - the essences of both full universalism and relativism being combined - or it may satisfy no-one.

The final concern raised by some researchers is the disquiet expressed by potential respondents over whether the research will benefit them (Benatar, 2002). Will their health or standard of living be improved, or will the information gathered from them - their responses or samples - be taken for analysis elsewhere by researchers they will never see again, leaving them no better off? Who, in short, is the research for - the researcher, those researched or both? Do we need a new ethics for research (Benatar and Singer, 2010; Chenall, Senior and Belton, 2011)?

\section{An alternative research-ethics framework: the ethics of Levinas}

'Research' is generally seen as the 'production of knowledge', which is conducted within an ethical framework based largely on a biomedical model that prioritises non-maleficence (doing no harm, primum non nocere) and leans strongly towards the universal application of Western ethical principles irrespective of the cultural or disciplinary setting in which they will be applied. The unpredictable and diverse processes of fieldwork may require a 
renegotiation and reconsideration of ethics in the field and hence a revised ethics committee approval, yet this is often impractical in the current one-stage, pre-research, review system. The current approach is consequentialist - ensuring the least harm to the greatest number - to be achieved deontologically by research ethics committees carrying out their prescribed legal and administrative duties and procedures. The protection from harm and financial or reputational penalty is, first, for the defence of the researcher, their institution and the research funder and only then for the individuals and communities being researched. Their protection is assumed to follow unproblematically from the initial ethical review.

Since the Belmont Report, social-science research has become far more reflexive and critical. Institutional review boards have been deemed out of tune with this demand for a non-violent transformative ethical consciousness (Lincoln and Cannella, 2009). While acknowledged for regulating procedural ethics, they have been criticised for an inflexible approach which sits uncomfortably in an era when research has come to be about understanding complexities and power structures. Institutional review boards have become places where regulations are enacted by elites far removed from the practices of research and hence ill placed to address the unheard voices of research participants (Cannella and Lincoln, 2004). The Belmont Report is too focused on regulating a vertical and hierarchical relationship between the researcher and what it refers to as 'research subjects' (Shore, 2006; Lincoln and Cannella, 2009). Ethics in institutional review boards has been criticised as being a symptom of the neoliberalisation of research (Cannella and Lincoln, 2007). The dominance of a Kantian approach has led to an ethical approach that intensifies an individualistic ethical framework. Ethics may need to adopt a relational approach between researcher and researched, both learning how to treat others equitably through dialogue and negotiation (Guillemin and Gillam, 2004; Cannella and Lincoln, 2007; Emmerich, 2013)

There is a radical alternative approach to research and research ethics that puts virtue ethics and the wellbeing of those to be researched - their unheard voices and unseen faces - at the heart of research. This is based on the work of the philosopher and Jewish theologian, Emmanuel Levinas (1906-1995). In his two major works - Totality and Infinity (1961) and Otherwise than Being (1974) - he outlines a theory of ethics that moves away from individuality and ego and suggests an ethics of alterity - an ethics for others. Unlike utilitarian and consequentialist ethical approaches, which emphasise rule-based methods, a Levinasian research-ethics strategy rejects an ethics of moral rules (Manderson, 2006). For Levinas, ethics is a responsibility to other people that is involuntary and singular. 'The demand of ethics comes from the intimacy of an experienced encounter, and its contours cannot therefore be codified or predicted in advance' (Bauman, 1993 in Manderson, 2006 p.8). In contrast to a Kantian moral framing based on rules, Levinas argues that ethics is about interpersonal relationships, not abstract principles; for him, an ethics based on universal first principles is a contradiction in terms.

For Levinas morality must be sought in what is Good but the problem is that the judgement of what is Good necessarily involves others who are distant from the individual and outside the scope of ontology. An inherent egocentrism towards individuals is at the heart of traditional ontology; for Levinas, to be means to be stuck in one's own being. Levinas reacts strongly against this singular and totalitarian approach and looks for the Good beyond one's being and finds it in the 'face of the Other'. The Other has its own dignity and therefore can demand to be respected; the face of the Other breaks down singularity and humanises the Self. The appeal of the Other to be 'loved' is so powerful that the Self becomes detached from its own being. A Levinasian research ethics would shift the focus from researchers as 
the guardians of a superimposed code of personal ethics to people who are obliged towards the Other (Hay, 1998).

Both Levinasian and Kantian approaches to research ethics highlight the importance of showing respect for others. While the Belmont Report calls for 'Respect for Persons', Levinas requires 'Respect the Other'. Autonomy is one of the most important principles in the Belmont Report. Autonomy and the idea of self-determination are central characteristics of the good life and in the Belmont Report we find a Kantian approach towards autonomy through, for example, the notion of a free decision to participate in research: the researcher does not coerce participants. Levinas's philosophy, on the other hand, is driven by the idea that heteronomy replaces autonomy, arguing that the subject (the researcher) must be subjected to the Other (the participant).

Levinas criticised Western philosophy for being focused on autonomy and 'totalising' (i.e. rejecting difference), for avoiding the complexity of reality and so being incapable of addressing our relations with others. Levinas contrasts this 'autonomous philosophy' and its continual return to the ego of the Self, with his 'heteronomic philosophy' that is based on the Other. The trope that Levinas employs to describe the encounter with the Other is the 'face'. In the chapter Ethics and the Face in Totality and Infinity Levinas (1961) uses the example of how the hunger seen in the face of the Other calls out to the Self. It is the proximity of the face that arrests the Self, even inducing paralysis (Bernasconi, 1995; Hofmeyr, 2007). "In a world of hunger, I am an oppressor" (Levinas 1961 p.200). The vulnerability experienced in the face of the Other commands a response from the Self. It is the face of the Other that allows a self-discovery through the 'pain' of the Other (Manderson, 2006).

Levinas explains the infinite responsibility of the Self for the Other through the concept of proximity which is understood by Levinas as implying simultaneously closeness and distance. The Other can be approached but is never reached. This ambiguity leads to infinite responsibility. Therefore our difference and distance from others indicate that it is impossible to cement our responsibility towards the Other in rules, logic or knowledge about the Other. Proximity, for Levinas, is about emotions, the body and the experience in the moment and that experience is not an abstract idea. In Levinasian ethics, a research relationship can be ethical only if its characteristics are not predetermined. If institutionalised ethical practices are centred round a standard contract setting out the parameters of an ethical relationship prior to an encounter with the Other, then they are the opposite of an ethical relationship.

For Levinas, the free will or autonomy of the participant is not guaranteed through the principle of prior informed consent; rather the opposite is true. By consenting to the research, the autonomy of the participant is violated because actions are driven by the researcher. Levinas criticises Greek philosophy because it protects the free will of the Self by neutralising the will of the Other who is 'captured' by the self. The justification for informed consent is that it protects free will and autonomy, and protects against deception and coercion (Kristinsson, 2009). Yet questions can still be raised about whether it can overcome the power relations embedded in research practices, despite the best of intentions. Levinas proposes the opposite - a research ethics ruled by the Other that can address the power relations and the other complaints against universal procedural ethics. Contrary to the Belmont Report, the starting point of a Levinasian ethics is a position of responsibility for the Other rather than starting from the position of autonomy. A Levinasian ethics can respond better than the Kantian approach to the call for social-science researchers to be more radical, 
egalitarian and anti-colonial because Levinas's starting point as first philosophy is heteronomy and not autonomy.

Anthropologists and ethnographers have found a Levinasian research ethics more appealing because it provides a framing that allows them to respond in the field to the demands of their research participants (Metro, 2014). Pre-formulated consent practices lose meaning once the ethnographer is confronted with unique situations set in local practices, vocabularies and customs. Ethnographers question whether everyone shares the capacity for autonomous decision-making (Benson and O'Neil, 2007; Metro, 2014). They contest the validity of a Cartesian model of subjectivity based on the principle that all individuals are autonomous and make rational decisions about how to interact, guided by a common belief in the universal principles of democracy and freedom. The consent form, they argue, should not be a straightjacket but should be the part of the research process that sets out the conditions for a relationship that should evolve once the research has started.

The requirement of flexibility is another reason why a dialogue with Levinas matters. This relates to the distinction between procedural and practical ethics. From a procedural perspective the current practice in institutional review boards may be adequate to deal with informed consent, confidentiality, rights to privacy, deception and protecting human subject from harm (Guillemin and Gillam, 2004). However, all researchers recognise that they will encounter tricky moments in the field. In the literature this is identified as situational ethics, referring to moments that are unexpected (Fletcher, 1966; Ellis, 2007). It is their unpredictability that makes them ethically important because, being unanticipated, they have not been discussed in institutional review boards. Nevertheless, these ethical moments still need a modus operandi. Ethics in practice, situational ethics or micro-ethics all refer to the unexpected moments in the field that demand an ethical reflection and action.

General rules and principles agreed in institutional review boards may not be helpful because the tricky moments usually occur as part of daily life during fieldwork (Banks et al 2013). This requires an 'ethical sensitivity to see the ethical salient features of situations and relational virtues such as trustworthiness' (Banks et al, 2013: p. 266). Virtue ethics and an ethics of care are often the primary moral drivers for such an engagement and such relationships come with responsibilities (Ellis, 2007; Rossman and Rallis, 2010; Banks et al, 2013). An ethics of care is based on the principles of mutual respect, dignity and connectedness. However, it is often part of a longer-term relationship and not all ethical moments present themselves between the researcher and the so-called research subjects. Often the trickiest moments occur during random encounters with those outside the approved research plan. An ethics of care is relational and therefore an improvement on individualbased ethics. But the starting point is still driven by the researcher: $\mathrm{s} / \mathrm{he}$ decides how to relate to the participants (Rossman and Rallis, 2010). An ethics of care requires the researcher to act with 'hearts and minds' (Slattery and Rap, 2003 in Banks et al, 2013). The danger is that the ethical moments in the field are seen as just dilemmas and the researcher follows her/his instinct. But for a reasoned moral decision, guidelines are needed on how to negotiate relationships as a precondition for ethical behaviour (Guillemin and Heggen, 2009). Ethical mindfulness is not a choice that should be left to the researcher on the spot. In a Levinasian approach it is no longer the researcher taking the decision on how to care for the Other: it is the Other demanding that the researcher fulfil their responsibility to look after the Other.

This alternative approach should nourish the relationship between researcher and participants based on an intersubjectivity that allows the researcher's Self to explore multiple forms of 
being through a discursive engagement with the Other (the research participant). Instead of giving a fixed meaning to an ethical relationship through a previously arranged consent form, an ethical relationship should emerge through dialogue during the research. What counts as ethical behaviour must not result from a monologue, because meaning does not reside only in the speaker. Language is interactive and meaning is formed through the interaction between the speaker and listener. Research ethics, for Levinas, should not be based on an assumption of shared meanings and understandings captured in a universal language of prior informed consent, but rather research ethics should 'become vehicles of constant semiotic negotiations' (Metro, 2014 p.178; Hill et al, 2010). As Judith Butler (2005) argues, a Levinasian ethics prevents totalising knowledge of the Other, that is, a systematic reduction of the Other (l'autre) to the same (le même). Extending this line of thinking, contract-based consent forms assume that all parties share the same meanings, language, priorities and understanding of research. However, as Sakai (1997) argues, a dialogical process is 'heterolingual', meaning that even with a common language researchers should act as though they are addressing a 'foreigner' because it would be unethical to predict the ethics or understandings of the research participants.

This makes for us a Levinasian ethics distinct from an ethics of care based on trust, friendship and long-term relationships. Even researchers who whole-heartedly embrace the principles of ethics of care, still question how far their responsibility towards the other should reach (Ritterbusch 2012). The reflections about positionality, caring after the fieldwork, reciprocity and considerations of participatory research are inadequate in a Levinasian ethics. For Levinas, we tend to totalise (simplify) the Other in one of two ways. Either we totalise them by keeping their strangeness at a distance and using a discourse that emphasises the differences and separation from us and defines the Other solely by their difference from us a form of relativism. Or we totalise the Other through discourses that accentuate sameness and union $-\mathrm{a}$ form of universalism (Manderson, 2006). We condemn the Other either to remain outside our comprehension because of their strangeness or we reduce the strangeness to sameness so that the Other becomes comprehensible. For Levinas, the former mistake is part of a tradition of deontological liberalism or a philosophy of rights in which the integrity and uniqueness of the Other is preserved and kept at a distance because its distinctiveness. The latter mistake is part of a tradition of teleological liberalism or utilitarianism as it preserves the equality of others to the Self because we share values and norms across society as a whole. Both use the Self as the starting point to build knowledge and this severely limits our opportunity to understand the Other because we either reduce everything to the same as us or to something wholly different. Totalising others in either way is unethical for Levinas.

This totalising process prevents us developing valid ethical relations with others. For Levinas, proximity is not physical closeness; it is a trope introduced by Levinas to convey responsibility. The proximity of the Other destabilises and decentres the ego. The presence of the Other excites us; it creates an obligation. The proximity of the Other makes us more aware of ourselves. However, from a Levinasian perspective, proximity is not only a social relationship. It is deeply physical; it is a sensation and an experience. Levinas refers to the excitement of the skin, like a blush when we are touched by the Other (Manderson, 2006 p.102). Writing from his own experience of the Holocaust, Levinas invokes the memory of those who were closest among the six million assassinated by the Nazis (Levinas, 1974 p.v). He clearly feels a unique and un-substitutable responsibility towards the victims of the Shoah. The proximity towards the Other raises an expectation of responsibility which is "unexceptionable [...] preceding every free consent, every pact, every contract" (Levinas, 
1974 p.114). How does this responsibility relate to research ethics and how does it go above and beyond an ethics of care?

The best way to describe this is the paralysis encountered during fieldwork by Vermeylen in Namibia, Botswana, Uganda, Ghana and Zambia over more than a decade. Most papers refer to ethical moments in the field directly related to their interactions, friendships and changing relationships during the fieldwork with their research participants. The encounters recalled here are those with 'strangers', people whom you meet in everyday life: at the bus stop, in the marketplace, or just passing by in the streets. Most of these fleeting moments were positive encounters but there have also been instances were patience was lost, distrust crept in and frustration was experienced. Sometimes someone hides the truth, spins a good story to make you feel guilty or provokes you to do unanticipated things. How can a Levinasian ethics help with these tricky moments? It may seem easier to get out of the situation if it is a stranger, but there are moments when close research collaborators and participants have behaved deceitfully or unethically. Will feelings of trust, friendship and ethics of care still give guidance now? These tricky moments paralyse researchers and only the face of the Other, the stranger will tell the researcher what they can and must do.

According to Levinas, the vulnerability experienced in the face of the Other commands a response from the Self, but not to impose, possess or assimilate the Other. It is the Other's face that allows a self-discovery through their 'pain' (Manderson, 2006). Although in Totality and Infinity (1961) hospitality is the welcome given to the Other who calls upon the Self to respond, it is still a host-guest relationship. In Totality and Infinity (1961) Levinas stresses the strangeness of the stranger that results in the Self being questioned and questioning him/herself in the face of the stranger. In Otherwise than Being (1974) this relationship becomes more risky as the host (the Self) may become hostage: not all encounters with the Other are benign. For Levinas this danger is a necessity as 'it is in the condition of being hostage that there can be in the world pity, compassion, pardon and proximity' (Levinas 1974, p.117). This shift is achieved through changing the positioning of the Other who is now close to the Self - a neighbour now whom one should not avoid.

Because of the Self's infinite responsibility towards the Other, the Self hosts the demands of the Other but equally is held hostage by these demands. The feeling of being a hostage to the vulnerability of the Other is at the core of consciousness, as it is for a child or parent. The infinite demands of the Other cannot be anticipated, may surprise us, may not be welcome but they are inevitable and therefore unpredictably difficult (Manderson, 2006).

A stronger challenge is being called upon to act when the norms encountered in the face of the Other are perceived as unethical. However, for Levinas the face indicates a relation of responsibility but he does not use it to give us specific moral obligations (Minister, 2012). The face does not reveal actual moral obligations or actions, but the 'practical demands [from the face] are derived from an interpretation of the possibilities for destitution within human existence' (Minister 2012, p.207). For Levinas, an ethical relationship is characterised by a close relationship between justice and forgiveness. Justice 'is called into being by this very mercy with a concern to recognise all the others...' (Levinas, 2001, p.230 in Slaughter, 2007, p. 50). The Self still has to use their judgement dictated by the vulnerability of the Other to choose the right response that meets Levinas's conception of an ethical relationship in the particular circumstances.

A Levinasian ethics asks us to think about ethics well beyond a rule-based duty in a specific research project. Particularly within the context of research projects in the global South, the 
purpose of research may be questioned. Is it only about generating knowledge and advancing science and careers or are wider issues at stake? Can and should research be about the needs of others and part of a restorative process after the injustices of totalising discourses (Young, 1990)? These are questions not usually considered in current ethics committees but they are precisely pointing out the responsibility Levinas is arguing for.

Applying a Levinasian ethics to social-science research implies a scepticism towards standard ethics forms, prior informed consent and other codified institutionalised rules based on preresearch (prospective) planning. Ethics is part of a general motivation to feel responsible for injustice. Ethics raises issues about the wider role of universities in society and the research they are facilitating. So far, this sense of responsibility can remain tucked away either in the unreported details of fieldwork or buried in our consciousness. Tricky moments of frustration or apathy can be airbrushed in fieldnotes, but for Levinas these are precisely when we should show our humanity and feel responsible for the wider injustices. On a personal note, there are moments when we have felt the urge to ask for forgiveness, as white, well educated Europeans. However often we asked for consent and recorded it, we remember the moments when we should have not shirked our responsibilities. We could have done more. Nobody has ever asked us where we have fallen short in the field, where we have avoided a request to help, where a blind eye was turned to someone who needed help. We could not have helped all who asked, but after engaging more deeply with Levinas's work it feels wrong to have silenced these moments and concerns.

\section{Discussion}

What makes Levinas' work distinctive is his idea that ethics should be the first moment in philosophy and hence in any research environment and not an afterthought or last-minute procedure. For Levinas, ethics is one's responsibility for others. It is not just situational, but is a "constitutive form of the human condition" (Benson and O'Neill, 2007 p.44). This means that the researcher's responsibility towards research participants is not based on reciprocity: the research participant can never be responsible for the researcher. As Levinas said in an interview:

The intersubjective relation is a non-symmetrical relation. It is precisely as the relationship between the Other and me is not reciprocal that I am subjected to no Other; and I am "subject" essentially in this sense. It is I who support all. (Levinas, 1985, p.95 in Benson and O’Neill, 2007, p.44).

For Barnett (2005), this quotation signifies that responsibility is infinite. It is also nonreciprocal because my responsibility does not rely on me expecting something back. Despite being a challenging ideal, a Levinasian ethic can usefully inform ethical possibilities when conducting fieldwork (Benson and O’Neill, 2007; Richardson-Ngwenya, 2012; Metro, 2014).

In summary, Levinas wants us to overcome totality (the rejection or overlooking of difference) (Benson and O'Neill, 2007). The researcher should be affected by the interpersonal relationship and so become self-reflective. S/he ought to challenge (historical) power relations when exposed to asymmetry and discomfort. Ethical sensibilities cannot be anticipated; they emerge only through encounters in the field. Ethical demands on the researcher do not always come from the research design; strangers can make a call on the researcher. Ethics is more than just predefining the researcher's ethical behaviour in the field; 
it is an experience of awaiting the call of responsibility that leads the researcher to be affected by others (Benson and O’Neill, 2007).

Being affected in the field by others means that research ethics committees should accept that their own ways of knowing and understanding, as well as the researcher's, can be challenged. Instead of focusing on detailed pre-research descriptions of consent forms and review of methodologies, research ethics committees would play a more useful role in the ethical process if their attention shifted to a post-research scrutiny of the researcher's responses to the many faces and voices of the research participants (perhaps messy, disorganised and contradictory) as encountered in the field. The unpredictability of the face-to-face encounter gets whitewashed away twice during the research process: first, during the institutional ethical-review process and, second, in the neat, cool, objective presentation and interpretation of the field notes and the interviews.

Changing one's research methodology is desirable, even essential, if circumstances in the field require it, such as working in another area if the weather changes or using a new source of information. One might change one's methods after discussions in the field: to overcome local objections to the original plan and so allow the research to proceed at all; to improve the range or quality of the information collected in ways not foreseen; or to take advantage of lines of enquiry or respondents unanticipated before the initial ethical review. So, changing one's research methodology may be just pragmatism after meeting the research participants. There can be no guarantee they will acquiesce to the researcher's approved plans. Klitzman and Appelbaum (2012) call for an audit of a sample of completed research projects to learn lessons from field practice. This is valuable but, we argue, is inadequate in scope (all projects should be reviewed afterwards and shown to be ethical) and inadequate philosophically (because changes in the field should go beyond what helps the researcher). Adopting Levinas's ethical view adds a principle and not just pragmatism. If one adopts a Levinasian philosophy of a love for others, one is duty bound to make changes in research methods to meet the requirements of those to be researched. The meaning of abstract concepts such as consent, harm, autonomy, risk, research or benefit can be negotiated only through face-toface encounters in the field. The researcher can respond ethically only when s/he faces in the moment the unpredictable words and actions of others.

A change to a pre-approved research plan - for whatever reason - strictly invalidates the initial ethical approval. If the methodology in practice differs from that approved the result is that, with only a one-stage ethical review procedure, the ethics committee cannot know whether the actual research was still ethical. Neither do the research funder nor the publisher of the research results have the necessary ethical assurance, because they rely on the ethics committee. Only a second-stage ethical review - after the research - can reinstate ethical confidence for all parties. Additionally a post-research ethical check provides an extra disincentive to any researcher tempted to depart from the approved plan in ways that might go against the ethical principles that underpinned their pre-research ethical review. The ethics committee's ultimate sanction on research changed in the field in ways that are unethical is to deny the researcher the authority to publish the material gathered by unapproved means.

The hard-pressed researcher might be concerned that an additional, post-research ethical review would add greatly to their workload. It need not. The only question the researcher would have to answer after the research had been completed would be whether the research departed materially from that approved. If the answer is 'no', that concludes the post- 
research ethical check. If the answer is 'yes', the researcher would be asked to describe the changes, justify them, and explain how the key ethical principles that informed the preresearch review were also upheld in the revised methodology. The assurance of ethical probity cannot be secured by only a pre-research review. The process of post-research ethical review need not be administratively burdensome. A post-research meeting between the researcher and the institutional ethics committee would be a learning experience for both as well as a clear reassurance to funders, publishers and the wider academic community. Only in this way can all parties be reassured that the research was carried out ethically.

\section{Funding}

The authors wish to thank the British Council for their support through the Developing Partnerships in Higher Education programme (DeLPHE grant 795).

\section{Acknowledgments}

The authors would like to thank the two anonymous reviewers for their insightful comments.

\section{References}

Adu-Gyamfi, J. (2014) Ethical challenges in cross-cultural field research: a comparative study of UK and Ghana. African Social Science Review, 7(1), 44-53.

Agulanna, C. (2010) The requirement of informed consent: procedure for implementing a crucial ethical norm in African communal culture. European Journal of Scientific Research 44(2), 204-219.

American Anthropological Association (1998). Code of Ethics. Available at: http://www.aaanet.org/issues/policy-advocacy/upload/ethicscode.pdf

Association of Social Anthropologists (1999). Ethical Guidelines for Good Research Practice. Brighton: Association of Social Anthropologists.

Atkinson, P. (2009). Ethics and ethnography. $21^{\text {st }}$ Century Society, 4(1), 17-30.

Banks, S., Armstrong, A., Carter, K., Graham, H., Hayward, P., Henry, A., Holland, T., Holmes, C., Lee, A., McNulty, A., Moore, N., Nayling, N., Stokoe, A. \& Strachan, A. (2013) Everyday ethics in community-based participatory research, Contemporary Social Science, 8(3) 263-277.

Barnett, C. (2005). Ways of relating: hospitality and the acknowledgement of otherness. Progress in Human Geography, 29(1), 5-21.

Bauman, Z. (1993) Postmodern Ethics. Oxford: Blackwell.

Belmont Report (1978). National Commission for the Protection of Human Subjects of Biomedical and Behavioral Research. Department of Health, Education and Welfare. (DHEW pub. no. (OS) 78-0012). Washington, DC: United States Government Printing Office. 
Benatar, S.R. (2002). Reflections and recommendations on research ethics in developing countries. Social Science \& Medicine, 54, 1131-1141.

Benatar, S.R., \& Singer, P.A. (2010). Responsibilities in international research: a new look revisited. Journal of Medical Ethics, 36, 194-197.

Benson, P., \& O’Neill, K., L. (2007). Facing risk: Levinas, ethnography, and ethics. Anthropology of Consciousness, 18(2), 29-55.

Bernasconi, R. (1995). "Only the Persecuted...." : Language of the oppressor, language of the oppressed. In A. Peperzak (Ed.) Ethics as First Philosophy: The significance of Emmanuel Levinas for philosophy, literature and religion. New York: Routledge. 77-86.

Bleek, W. (1987). Lying informants: a fieldwork experience from Ghana. Population and Development Review, 13(2), 314-322.

Bond, T. (2012). Ethical imperialism or ethical mindfulness? Rethinking ethical review for social sciences. Research Ethics, 8(2), 97-112.

Butler, J. (2005). Giving an account of oneself. New York: Fordham University Press.

British Sociological Association (2002/4). Statement of Ethical Practice. Durham: British Sociological Association.

Cannella, G.S. \& Lincoln, Y.S. (2004). Epilogue: Claiming a critical social science reconceptualising and redeploying research. Qualitative Inquiry, 10(2), 298-309.

Cannella, G.S. \& Lincoln, Y.S. (2007). Predatory vs. Dialogic Ethics: Constructing an illusion or ethical practice as the core of research methods. Qualitative Inquiry, 13(3), 315335 .

Chenhall, R., Senior, K., \& Belton, S. (2011). Negotiating human research ethics. Anthropology Today, 27(5), 13-17.

Colnerud, G. (2015). Ethical dilemmas in research in relation to ethical review: an empirical study. Research Ethics, 10(4), 238-253.

Corradetti, C. (2009). Relativism and Human Rights: a Theory of Pluralistic Universalism. Dordrecht: Springer.

Crabtree, S.A. (2013). Research ethics and the moral enterprise of ethnography: conjunctions and contradictions. Ethics and Social Welfare, 7(4), 359-378.

Dench, S., Iphofen, R., \& Huws, U. (2004). An EU Code of Ethics for Socio-Economic Research. Brighton: Institute for Employment Studies.

Dingwall, R. (2008). The ethical case against ethical regulation in humanities and social science research. $21^{\text {st }}$ Century Society, 3(1), 1-12. 
Economic and Social Research Council (2005). Research Ethics Framework. Swindon: Economic and Social Research Council. (Revised in 2010).

Emmerich, N. (2013). Between the accountable and the auditable: ethics and ethical governance in the social sciences, Research Ethics, 9(4), 175-186.

Ellis, C. (2007). Telling secrets, revealing lives: relational ethics in research with intimate others, Qualitative Inquiry, 13(1), 3-29.

Fletcher, J. (1966). Situation Ethics: the New Morality. Philadelphia: Westminster Press.

Guillemin, M. \& Gillam, L. (2004) Ethics, Reflexivity, and "Ethically Important Moments" in Research. Qualitative Inquiry, 10(2), 261-280.

Guillemin, M. \& Heggen, K. (2009). Rapport and respect: negotiating ethical relations between researcher and participant. Medical Health Care and Philosophy, 12, 291-299.

Haggerty K.D. (2004). Ethics creep: governing social science research in the name of ethics. Qualitative Sociology, 27(4), 391-413.

Hammersley, M. (2009). Against the ethicists: on the evils of ethical regulation. International Journal of Social Science Methodology, 12(3), 211-225.

Hammersley, M. (2015). On ethical principles for social research. International Journal of Social Research Methodology, 18(4), 433-449.

Hammersley, M. \& Traianou A. (2011) Moralism and research ethics: a Machiavellian perspective. International Journal of Social Research Methodology, 14(5), 379-390.

Hay, I. (1998). Making moral imaginations. Research ethics pedagogy, and professional human geography. Philosophy \& Geography, 1(1), 55-75.

Hedgecoe, A. (2008). Research ethics review and the sociological research relationship. Sociology, 42(5), 873-886.

Hill, Z., Tawiah-Agyemang, C., Odei-Danso, S., \& Kirkwood, B. (2010). Informed consent in Ghana: what do participants really understand? Journal of Medical Ethics, 34, 48-53.

Hofmeyr, B. (2007). Radical passivity: Ethical problem or solution? A preliminary investigation. South African Journal of Philosophy, 26(2), 150-162.

Israel, M. (2014). Research Ethics and Integrity for Social Scientists: Beyond Regulatory Compliance. London: Sage Publications $2^{\text {nd }}$ edition.

Jennings, S. (2012). Response to Schrag: what are ethics committees for anyway? A defence of social science research ethics review. Research Ethics, 8(2), 87-96.

Klitzman, R. \& Appelbaum P.S. (2012) To protect human subjects, review what was done, not proposed. Science 335 (6076) 1576-7. 
744 Kristinsson, S. (2009) The Belmont report's misleading conception of autonomy. Virtual

Mentor, 11(8), 611-616.

Krosin, M.T., Klitzman, R., Levin, B., Cheng, J., \& Ranney, M.L. (2006). Problems in comprehension of informed consent in rural and peri-urban Mali, West Africa. Clinical Trials, 3, 306-313.

Leaning, J. (1996). Not unique to one place or time: they could happen here. British Medical Journal 313:1413. Available at http://www.bmj.com/content/313/7070/1413

Levinas, E. (1961). Totality and Infinity. An Essay on Exteriority. Pittsburgh: Duquesne University Press. Transl. A. Lingis (1969).

Levinas, E. (1974). Otherwise Than Being or Beyond Essence. Pittsburgh: Dusquesne University Press. Transl. A. Lingis (1998).

Levinas, E. (1985). Ethics and Infinity: Conversations with Philippe Nemo. Richard A. Pittsburgh: Duquesne University Press. Transl. Cohen.

Levinas, E. (2001). Is it Righteous to be? Interviews with Emmanuel Levinas. Stanford: Stanford University Press.

Librett, M., \& Perrone, D. (2010). Apples and oranges: ethnography and the IRB. Qualitative Research, 10(6), 729-747.

Lincoln, Y.S. \& Cannella, G.S. (2009) Ethics and the broader rethinking/reconceptualization of research as construct, Cultural Studies $\Leftrightarrow$ Critical Methodologies, 9(2), 273-285.

London, A.J. (2012). A non-paternalistic model of research ethics and oversight: assessing the benefits of prospective review. Journal of Law, Medicine and Ethics, 40(4), 930-944.

MacIntyre, A. (1985). After Virtue: a Study in Moral Theory. London: Duckworth.

Manderson, D. (2006). Proximity, Levinas, and the Soul of Law. Montréal \& Kingston: McGill-Queen's University Press.

McAreavey, R., \& Muir, J. (2011). Research ethics committees: values and power in higher education. International Journal of Social Research Methodology, 14(5), 391-405.

Metro, R. (2014). From the form to the face to face: IRBs, ethnographic researchers, and human subjects translate consent. Anthropology \& Education Quarterly, 45(2), 167-184.

Milgram, S. (1974). Obedience to Authority: an Experimental View. London: Tavistock.

Minister, S. (2012). De-facing the Other: Reason, Ethics \& Politics of Difference.

Milwaukee: Marquette University Press. 
Monaghan, L.F., O’Dwyer, M., \& Gabe, J. (2013). Seeking university Research Ethics Committee approval: the emotional vicissitudes of a 'rationalised' process. International Journal of Social Research Methodology, 16(1), 65-80.

National Commission for the Protection of Human Subjects of Biomedical and Behavioral Research (1979), The Belmont Report: Ethical Principles and Guidelines for the Protection of Human Subjects of Research, Department of Health, Education and Welfare.

Pirrie, A., MacAllister, J \& Macleod, G. (2012) Taking flight: trust, ethics and the comfort of strangers. Ethics and Education 7(1) 33-44.

Pollock, K. (2012). Procedure versus process: ethical paradigms and the conduct of qualitative research. BMC Medical Ethics 13, 25. Available at http://www.biomedcentral.com/1472-6939/13/25

Richardson-Ngwenya, P. (2012). The affective ethics of participatory video: an exploration of inter-personal encounters, ACME: An International E-Journal for Critical Geographies, 11(2), 250-281.

Ritterbusch, A. (2012). Bridging guidelines and practice: toward a grounded care ethics in youth participatory action research. The Professional Geographer, 64(1), 16-24.

Rossman, G.B. \& Rallis, S.F. (2010) Everyday ethics: reflections on practice, International Journal of Qualitative Studies in Education, 23(4) 379-391.

Sakai, N. (1997). Translation and Subjectivity: On "Japan” and cultural nationalism. Minneapolis: University of Minnesota Press.

Schrag, Z.M. (2011). The case against ethics review in the social sciences. Research Ethics, 7(4), 120-131.

Schüklenk, U. (2000). Protecting the vulnerable: testing times for clinical research ethics. Social Science and Medicine, 51, 969-977.

Shore, N. (2006) Re-conceptualizing the Belmont Report, Journal of Community Practice, 14(4), 5-26.

Slaughter, M. (2007). Levinas, Mercy, and the Middle Ages. In M. Diamantides (ed.)

Levinas, Law, Politics. Abingdon, Oxon: Routledge-Cavendish. 49-69.

Slattery, P. \& Rapp, D. (2003). Ethics and the foundation of education: teaching convictions in a postmodern world. Boston: Allyn \& Bacon.

Smythe, W.E., \& Murray, M.J. (2000). Owning the story: ethical considerations in narrative research. Ethics and Behaviour, 10(4), 311-336. 
836 Stanley, L. \& Wise, S. (2010). The ESRC's 2010 Framework for Research Ethics: Fit for

837 Research Purpose? Sociological Research Online 15(4) 12. Available from

838 http://www.socresonline.org.uk/15/4/12.html

839

840

Weijer, C. (1999). Protecting Communities in Research: Philosophical and Pragmatic

841

842 Challenges. Cambridge Quarterly of Healthcare Ethics, 8, 501-513.

Weinstein, M. (2008). Captain America, Tuskegee, and righteous guinea pigs: Considering scientific ethics through official and subaltern perspectives, Science \& Education, 17, 961975.

Wiles, R., \& Boddy, J. (2013). Research ethics in challenging contexts. Methodological Innovations Online, 8(2), 1-5.

849

850 Young, I., M. (1990). Justice and the Politics of Difference. Princeton: Princeton University 851 Press. 